\title{
Popular psychological myths: A comparison of students' beliefs across the psychology major
}

\begin{abstract}
Catherine M. Gaze ${ }^{1}$
Abstract: The present study investigates the frequency and confidence with which college students endorse popular psychological myths, contrasting introductory psychology students (at the beginning and end of the course) with upper-level psychology majors and students who have never taken Introduction to Psychology. This study builds on the existing literature by comparing these groups of students and considering the role of confidence. While majors endorsed fewer myths than students with less psychology course experience, majors still endorsed half of the myths. Consistent with previous work, students reported a similar number of myths before and after completing Introductory Psychology, but students were less confident in their wrong answers at the end of the semester. While the present study focuses on myths in psychology, implications for teaching apply across disciplines.
\end{abstract}

Keywords: pedagogy, myths, misconceptions

\section{Introduction}

The topic of psychological myths and misconceptions has been studied by researchers in the field of the teaching of psychology for several decades (e.g. McKeachie, 1960). Although the specific items included on measures of psychological misconceptions have changed over time, and have sometimes been found to be discrepant across measures (see Griggs \& Ransdell, 1987), the underlying topic remains of interest to teachers of psychology. There has been a recent renewed attention to the topic of misconceptions and recommendations for faculty to incorporate this information into psychology courses (e.g. Lilienfeld, 2010). Lilienfeld (2010) summarizes previous work on individual myths to highlight the significance of these topics for psychology courses. Kuhle and colleagues studied the potential impact of these myths on student performance and found a negative correlation between the number of myths endorsed at the beginning of the semester and students' performance in the Introduction to Psychology course (Kuhle, Barber, \& Bristol, 2009). Psychology instructors are not only concerned with students' performance in Psychology courses, but also what knowledge students take from their courses to apply to life outside of the classroom. We want our students to appreciate the science of psychology and to be able to critically evaluate claims. While the topic of addressing misconceptions about the field is not unique to Psychology, with the nature of the topics covered within the field of Psychology, students may be more likely to base judgments on their own experiences or other non-empirical sources.

Data on the prevalence of psychological misconceptions suggests that many students entering Introductory Psychology courses endorse a majority of these myths $(38.5 \%$ accuracy, Taylor \& Kowalski, 2004; 30\% Kowalski \& Taylor, 2009). Some studies have compared

\footnotetext{
${ }^{1}$ Elmhurst College. Correspondence concerning this article should be addressed to: Catherine Gaze, Department of Psychology, 190 S. Prospect Ave, Elmhurst, IL 60126. Email: gazec@elmhurst.edu
} 
students at the beginning and end of Introductory Psychology; McKeachie (1960) and Vaughan (1977) documented little change in performance between the beginning and end of Introductory Psychology. Kowalski and Taylor found an improvement to 64\% accuracy using a mythsfocused section of the course. While it is expected that our advanced majors would endorse fewer of these myths as their psychology experience has increased, few studies have investigated the prevalence of myths and misconceptions across the psychology major. One study that investigated the impact of college psychology courses on myths found that students' belief in myths (measured using a 20-item scale) decreased with the number of college courses (but not junior college courses) completed (Standing \& Huber, 2003). Understanding how these myths are endorsed across the major helps to inform where and how discussions of myths and misconceptions in the field may be most beneficial to students.

One criticism of previous research on psychological misconceptions has addressed the true/false format of many of these measures (Brown, 1984; Ruble, 1986), with one set of researchers adding a "don't know" option (Gardner \& Dalsing, 1986). Taylor and Kowalski (2004) reported confidence scores for their items (originally 1-10 but then collapsed to 3 categories for analysis), with high confidence in correct answers at post-test. While this confidence rating has not been widely used in studies of misconceptions, it addresses an important critique of the true/false format. In a true/false format it is impossible to distinguish between a belief that is strongly held (a true misconception) or a random guess. For this reason, the current study incorporates a confidence rating and specifically addresses items that are both incorrectly and confidently answered.

The goal of the present study is to develop a greater understanding of the myths students endorse with varying levels of psychology course experience. This extends findings from previous work by contrasting students with different levels of experience and examining how confidence in responses is affected by psychology course experience. The present study assesses the frequency and confidence with which college students endorse common psychological myths, contrasting; 1) Introductory Psychology students at the beginning of the course 2) Introductory Psychology students at the end of the course, 3) Advanced Psychology majors and 4) students who have never taken a Psychology course. It is expected that these different groups should exhibit different belief patterns. Specifically, it is expected that more psychology experience (more courses) should lead to lower myth endorsement. Furthermore, it is expected that these educational experiences will similarly affect the degree of confidence these students have in these myths.

\section{Method}

\section{Participants}

Students from a small Midwest college were invited to participate in the study in exchange for entry into a lottery for gift-cards. Thirty-three students enrolled in Introduction to Psychological Science (Intro Psych) chose to complete the questionnaire at the beginning of the semester, and 21 of those students $(63.6 \%)$ returned to complete the questionnaire at the end of the semester. Twenty-nine advanced psychology majors (defined as having completed the research methods course) participated in the study. Students who had never taken a college psychology course were also recruited through flyers and announcements in classes across 
campus (No Psych; n=14). As shown in Table 1, with the exception of the advanced student group, most participants were first year students.

Table 1

Demographics and total number of myths correctly recognized

\begin{tabular}{lccccc}
\hline Group & $\mathrm{N}$ & $\begin{array}{c}\text { Year in } \\
\text { school }\end{array}$ & $\begin{array}{c}\text { \% completed } \\
\text { high school } \\
\text { psychology }\end{array}$ & $\begin{array}{c}\text { Average } \\
\text { Number of } \\
\text { Myths } \\
\text { Correct (SD) } \\
\text { Max }=45\end{array}$ & $\begin{array}{c}\text { Average } \\
\text { Confidence } \\
\text { (SD) } \\
\text { Max }=3\end{array}$ \\
\hline Intro Psych (pre) & 33 & $\begin{array}{c}73 \% \text { first } \\
\text { year } \\
86 \% \text { first } \\
\text { year }\end{array}$ & $29 \%$ & $17.95(4.72)$ & $2.02(0.27)$ \\
Intro Psych (post) & 21 & $\begin{array}{c}76 \% \\
\text { seniors }\end{array}$ & $51 \%$ & $22.41(7.71)$ & $2.19(0.26)$ \\
Advanced Majors & 29 & $\begin{array}{c}64 \% \text { first } \\
\text { year }\end{array}$ & $50 \%$ & $20.14(6.00)$ & $2.09(0.22)$ \\
No Psych & 14 & & & \\
\hline
\end{tabular}

\section{Materials}

A modified version of Kowalski and Taylor's (2009) questionnaire was used. The 45 myth items from their questionnaire were combined with five true statements to create a 50-item questionnaire (see Appendix). Each item was presented in a true/false format, consistent with the original questionnaire. Students were also asked to rate their confidence for each item on a three-point scale. Additionally, the participants were asked to select one specific item and identify the source of the information they used to respond to that item. On the end of the semester questionnaire, Intro Psych students were asked whether or not each item was covered in their Intro Psych course.

Questionnaires were scored by counting the number of items answered correctly (appropriately identifying the statement as a myth or a fact). Only the 45 myth items are reported here to be consistent with previous studies. Additionally, responses that were both incorrect and rated as highly confident (rated as 3 out of 3 ) were identified.

\section{Procedure}

Students were recruited from nine different Introduction to Psychological Science classes during first two weeks of the semester to complete the pre-test. These Intro Psych students were then contacted at the end of the semester and invited to complete the survey during the last week of classes. Advanced Psychology students were recruited through upper level courses at the beginning of the semester. Students with no college level psychology experience were recruited through campus flyers, announcements in courses, and a table in the cafeteria. All questionnaires were administered in group sessions in paper and pencil format to prevent students from looking up the answers on a computer while completing the questionnaire. 


\section{Results}

\section{Total Number of Myths Endorsed}

As shown in Table 1, students recruited at the beginning of Introduction to Psychological Science answered an average of $17.76(S D=4.99)$ items correctly out of 45 questions, or $39.5 \%$. This is slightly higher than the 30\% reported by Kowalski and Taylor (2009) using the same measure at the beginning of their introductory courses. By the end of the semester, students performed similarly, answering $17.95(S D=4.72)$ items correctly, or $39.9 \%$. Students with no psychology courses answered an average of $20.14(\mathrm{SD}=6.0)$ items correctly, or $45 \%$. Advanced students answered an average of $22.41(\mathrm{SD}=7.71)$ items correctly, 49.8\%. A univariate analysis of variance indicated a significant difference in total items correct by group, $F(2,73)=4.54, p=$ $.014, \eta^{2}=.11$. Post-hoc analysis indicated a significant difference between the Introduction to Psychological Science students and advanced psychology majors $(p=.01)$, with Advanced majors answering more items correctly. Interestingly, there was no significant difference in performance between students (Intro and No Psych) who completed high school psychology and those who had no prior psychology experience $(t(45)=1.52, p=.13)$.

\section{Confidence in Responses}

Analyses were also conducted to assess the degree of confidence in responses. An average confidence score was created for each student. A univariate analysis of variance indicated a significant difference among the groups in their average confidence $F(2,73)=5.40$, $p=.007, \eta^{2}=.13$, with post-hoc analysis indicating advanced students were significantly more confident in their responses than beginning introductory students $(p=.007)$, but interestingly no difference was found in confidence between advanced students and students with no psychology courses.

Items that students answered incorrectly but confidently (score of 3 ) were of interest, as these exemplify endorsement of a myth, not just a random guess. First, myths that received no incorrect/confident responses were identified. For beginning introductory psychology students, five myths received no incorrect and confident responses (See Table 2) and these myths were confidently endorsed by very few students across groups. Some of these myths were still answered incorrectly by students, but no students were confident in these wrong answers.

In contrast, five myths were identified as being answered incorrectly and confidently by a majority (51\% or more) of the group (see Table 3 ). These same five items were answered incorrectly by more than $90 \%$ of the class. At the end of the semester, a majority of Intro Psych students only answered two myths incorrectly and confidently. These same two myths were the only two endorsed by a majority of advanced majors as wrong and confident.

\section{Sources of Misconceptions}

Students were asked to select one item for which they knew the source of their information. Overall, only $56 \%$ of students answered the question they selected correctly, with advanced students more likely to answer the item they selected correctly than beginning Intro Psych students, $t(45)=-2.53, p=.015, d=.72$. More advanced students were also more likely to than Intro Psych students to cite a previous class as the source of their information (83\% and 
Gaze, C.M.

$61 \%$ respectively) and less likely to cite personal experience than Intro Psych students (10\% and $30 \%$ respectively).

Table 2

Myths with no incorrect and confident responses by beginning intro psych students

\begin{tabular}{lllll}
\hline Myth & \multicolumn{4}{c}{$\%$ Wrong and Confident } \\
\cline { 2 - 5 } & $\begin{array}{l}\text { Intro Pre } \\
(\mathrm{n}=33)\end{array}$ & $\begin{array}{l}\text { Intro Post } \\
(\mathrm{n}=21)\end{array}$ & $\begin{array}{l}\text { Advanced } \\
(\mathrm{n}=29)\end{array}$ & $\begin{array}{l}\text { No Psych } \\
(\mathrm{n}=14)\end{array}$ \\
\hline $\begin{array}{l}\text { We experience stress even when good } \\
\text { things happen to us (reverse score) }\end{array}$ & 0 & 0 & $7 \%$ & $7 \%$ \\
$\begin{array}{l}\text { Human memory works like a tape } \\
\text { recorder or video camera, and accurately }\end{array}$ & 0 & 0 & 0 & 0 \\
$\begin{array}{l}\text { records the events we have experienced. } \\
\begin{array}{l}\text { During sleep, your brain rests. } \\
\text { Many adults were abused as children but } \\
\text { do not remember the abuse }\end{array}\end{array}$ & 0 & 0 & $3 \%$ & 0 \\
$\begin{array}{l}\text { If you live long enough, you will } \\
\text { eventually develop dementia. }\end{array}$ & 0 & $5 \%$ & $10 \%$ & $14 \%$ \\
\hline
\end{tabular}

Table 3

Myths answered incorrectly and confidently by majority of beginning intro psych students

\begin{tabular}{lllll}
\hline Myth & \multicolumn{3}{c}{$\%$ Wrong and Confident } \\
\cline { 2 - 5 } & $\begin{array}{l}\text { Intro Pre } \\
(\mathrm{n}=33)\end{array}$ & $\begin{array}{l}\text { Intro Post } \\
(\mathrm{n}=21)\end{array}$ & $\begin{array}{l}\text { Advanced } \\
(\mathrm{n}=29)\end{array}$ & $\begin{array}{l}\text { No Psych } \\
(\mathrm{n}=14)\end{array}$ \\
\hline $\begin{array}{l}\text { If you're unsure of your answer while } \\
\text { taking a test, it's best to stick with your } \\
\text { initial hunch. }\end{array}$ & $52 \%$ & $33 \%$ & $45 \%$ & $64 \%$ \\
$\begin{array}{l}\text { Subliminal messages can be used to } \\
\text { persuade others to purchase products. }\end{array}$ & $55 \%$ & $43 \%$ & $41 \%$ & $57 \%$ \\
$\begin{array}{l}\text { Most people who use heroin become } \\
\text { addicted to it. }\end{array}$ & $55 \%$ & $52 \%$ & $59 \%$ & $43 \%$ \\
$\begin{array}{l}\text { Immediate contact between a mother and } \\
\text { infant after birth is critical for bonding }\end{array}$ & $61 \%$ & $57 \%$ & $59 \%$ & $29 \%$ \\
$\begin{array}{l}\text { Most women experience a marked } \\
\text { worsening of their moods during the } \\
\text { premenstrual period. }\end{array}$ & $52 \%$ & $38 \%$ & $45 \%$ & $36 \%$ \\
\hline
\end{tabular}

Journal of the Scholarship of Teaching and Learning, Vol. 14, No. 2, May 2014. 


\section{Intro Psych Students at the Beginning and End of the Semester}

Within-subject analyses were possible with 21 Intro Psych students who returned to complete the same measure during the last week of classes. As noted above, their mean score on the 45 myths was similar to their performance at the beginning of the semester. One possible explanation for a lack of change in performance may be that many of these myths are not covered in traditional Introduction to Psychology classes. In order to assess this, students were asked to report whether or not each item was covered in their class. Interestingly, only 17 of the myths were reported by a majority (51\%) of students as covered in their Introduction to Psychological Science, and only 10 myths were reported as being covered by $75 \%$ or more of the students.

Of particular interest in this subset of students were items in which there was substantial change (either positive or negative) at the end of the semester. Five myths for which the majority of changes in responses were from incorrect to correct ("positive change") are identified in Table 4. The percent of students who reported discussing each myth in their class is also reported in this table. For example, $81 \%$ of students reported discussing the reliability of eyewitness testimony in their course, while only $29 \%$ reported discussing whether opposites attract.

Five myths were also identified as "negative change" items (see Table 5). Although 95\% of the students reported discussing information related to attachment, five of the seven students who changed their responses from the beginning of the semester, made an incorrect change, endorsing the myth that attachment is based on the mother filling the physiological need for food, at the end of the semester.

\section{Advanced Psychology Students}

While advanced students performed better than Intro Psych students and No Psych students, several myths were endorsed by a substantial percentage of the advanced students. Overall, 12 of the 45 items were answered correctly by less than 1/3 of the group. For example, $76 \%$ of advanced students endorsed the myth that hypnosis is useful for retrieving forgotten memories, $45 \%$ percent of the advanced students endorsed the myth that we only use $10 \%$ of our brain, and $34 \%$ believe memory works like a tape-recorder or video camera.

\section{Discussion}

The results of this study contribute to our understanding of undergraduate students' endorsements of popular misconceptions. While this study specifically addresses psychology myths, several of the findings have implications for the identification of myths across disciplines. With a better understanding of the misconceptions with which students enter the classroom, more effective pedagogy can be developed.

Psychology majors who had completed more coursework did correctly identify more items as myths than students with less psychology course experience, but these students still scored relatively low (only around 50\% correct). Consistent with previous work, a college level introductory psychology class did little to convince the students to reject commonly held psychological myths. In fact, students who completed an introductory psychology class were indistinguishable from non-psychology students who never took the class. One area in which 
students did improve (both at the end of Introduction to Psychological Science and as advanced majors) was the certainty with which they answered items incorrectly. While the number of myths they endorsed did not change significantly, they were less confident in their misconceptions after being exposed to psychology courses. This confidence rating adds an important to dimension to the true/false format, which otherwise could simply reflect random guessing. While students across the groups endorsed many misconceptions, only five misconceptions were rated as incorrect and confident by a majority of students. Given that the majority of studies that address myths have focused on the true/false format, this is an important consideration for the identification of myths across disciplines.

Table 4

Positive Change Items for Intro Psych Students

\begin{tabular}{|c|c|c|c|c|c|c|}
\hline \multirow[b]{2}{*}{ Myth } & \multirow[b]{2}{*}{$\begin{array}{l}\text { Number } \\
\text { of answers } \\
\text { changed } \\
\text { to correct } \\
\text { after Intro }\end{array}$} & \multirow[b]{2}{*}{$\begin{array}{l}\% \text { who } \\
\text { reported } \\
\text { covering } \\
\text { the topic } \\
\text { in Intro }\end{array}$} & \multicolumn{4}{|c|}{$\%$ Answered Correctly } \\
\hline & & & $\begin{array}{l}\text { Intro Pre } \\
(\mathrm{n}=21)\end{array}$ & $\begin{array}{l}\text { Intro } \\
\text { Post (n } \\
=21)\end{array}$ & $\begin{array}{c}\text { Advanced } \\
(\mathrm{n}=29)\end{array}$ & $\begin{array}{c}\text { No Psych } \\
(\mathrm{n}=14)\end{array}$ \\
\hline $\begin{array}{l}\text { Playing classical music } \\
\text { (e.g., Mozart) to infants } \\
\text { and children increases } \\
\text { their intelligence. }\end{array}$ & $\begin{array}{c}5 \text { of } 7 \\
\text { changes }\end{array}$ & $43 \%$ & $29 \%$ & $43 \%$ & $69 \%$ & $21 \%$ \\
\hline $\begin{array}{l}\text { Eyewitness testimony is } \\
\text { usually reliable } \\
\text { ( } 5 \text { of } 7 \text { changes correct) }\end{array}$ & $\begin{array}{c}5 \text { of } 7 \\
\text { changes }\end{array}$ & $81 \%$ & $52 \%$ & $67 \%$ & $79 \%$ & $71 \%$ \\
\hline $\begin{array}{l}\text { All effective } \\
\text { psychotherapies force } \\
\text { individuals to confront } \\
\text { the "root" causes of } \\
\text { their problems in } \\
\text { childhood ( } 5 \text { of } 8 \\
\text { changes correct) }\end{array}$ & $\begin{array}{c}5 \text { of } 8 \\
\text { changes }\end{array}$ & $76 \%$ & $43 \%$ & $52 \%$ & $48 \%$ & $36 \%$ \\
\hline $\begin{array}{l}\text { Most people only use } \\
10 \% \text { of their brains ( } 6 \\
\text { changes, all correct) }\end{array}$ & $\begin{array}{c}6 \text { of } 6 \\
\text { changes }\end{array}$ & $52 \%$ & $29 \%$ & $57 \%$ & $55 \%$ & $50 \%$ \\
\hline $\begin{array}{l}\text { Opposites attract ( } 9 \text { of } \\
12 \text { changes correct) }\end{array}$ & $\begin{array}{l}9 \text { of } 12 \\
\text { changes }\end{array}$ & $29 \%$ & $33 \%$ & $62 \%$ & $59 \%$ & $50 \%$ \\
\hline
\end{tabular}


Gaze, C.M.

Table 5

Negative Change Items for Intro Psych Students

\begin{tabular}{|c|c|c|c|c|c|c|}
\hline \multirow[b]{2}{*}{ Myth } & \multirow[b]{2}{*}{$\begin{array}{l}\text { Number } \\
\text { of answers } \\
\text { changed } \\
\text { to wrong } \\
\text { after Intro }\end{array}$} & \multirow[b]{2}{*}{$\begin{array}{l}\% \text { who } \\
\text { reported } \\
\text { covering } \\
\text { the topic } \\
\text { in Intro }\end{array}$} & \multicolumn{4}{|c|}{ \% Answered Correctly } \\
\hline & & & $\begin{array}{c}\text { Intro Pre } \\
(\mathrm{n}=21)\end{array}$ & $\begin{array}{c}\text { Intro } \\
\text { Post (n } \\
=21)\end{array}$ & $\begin{array}{l}\text { Advanced } \\
(\mathrm{n}=29)\end{array}$ & $\begin{array}{c}\text { No Psych } \\
(\mathrm{n}=14)\end{array}$ \\
\hline $\begin{array}{l}\text { ESP has been } \\
\text { empirically documented }\end{array}$ & 6 of 8 & $33 \%$ & $76 \%$ & $57 \%$ & $59 \%$ & $64 \%$ \\
\hline $\begin{array}{l}\text { Human memory works } \\
\text { like a tape recorder or } \\
\text { video camera, and } \\
\text { accurately records the } \\
\text { events we have } \\
\text { experienced }\end{array}$ & 4 of 5 & $86 \%$ & $95 \%$ & $81 \%$ & $66 \%$ & $71 \%$ \\
\hline $\begin{array}{l}\text { Clinical judgment and } \\
\text { intuition are the best } \\
\text { means of combining } \\
\text { information to reach a } \\
\text { diagnosis for a patient }\end{array}$ & 8 of 10 & $29 \%$ & $62 \%$ & $33 \%$ & $55 \%$ & $36 \%$ \\
\hline $\begin{array}{l}\text { People's responses to } \\
\text { inkblots tell us a great } \\
\text { deal about their } \\
\text { personalities and } \\
\text { propensities toward } \\
\text { mental disorders. }\end{array}$ & 6 of 8 & $95 \%$ & $29 \%$ & $10 \%$ & $34 \%$ & $36 \%$ \\
\hline $\begin{array}{l}\text { A baby's attachment for } \\
\text { its mother is based on } \\
\text { mom's filling the } \\
\text { physiological need for } \\
\text { food. }\end{array}$ & 6 of 7 & $95 \%$ & $38 \%$ & $14 \%$ & $41 \%$ & $57 \%$ \\
\hline
\end{tabular}

For the teaching of psychology, it is helpful to examine the specific myths endorsed. Most students (Intro and No Psych) correctly answered items related to memory. However, myths about clinical judgment and developmental issues were frequently endorsed, even among psychology majors. These myths are particularly concerning due to their potential impact on people's behavior. For example, one of the most strongly endorsed myths was related to immediate contact between a mother and infant. Well-meaning individuals may share this with expectant parents. In cases where immediate contact between mother and child is not possible due to medical complications, parents may already be looking for evidence that their child is not attached to them and consequently change their own behavior toward the child. In contrast, some other myths are less harmful. One of the most strongly endorsed myths was that related to the addictiveness of heroin. Individuals who believe this myth will be less likely to try heroin 
and may discourage others from trying also so that in this case endorsement of the myth may result in less dangerous behavior.

One strength of the current study is that the students were sampled across Introductory Psychology sections and do not reflect a single instructor's coverage of the material. One finding that may inform previous reports of a lack of change in students after completion of an Introductory course is that only 10 of 45 myths used in the present study were reported by students as being addressed in their Introductory course. While individual instructors may choose to emphasize some material over other in the interest of time, it is critical for instructors to be aware of the biases and misinformation with which their students are entering the course, and for instructors of advanced courses cannot take for granted that information was covered previously. In the current study, this information is based only on student report. In future research it would be beneficial to also have instructors provide a rating of the topics they believe they covered in the course.

The data from this study add to our understanding of the prevalence of these myths across the major. The myths endorsed by the advanced majors and Intro students who reported discussing the topic in their course but still answered incorrectly point to the ineffectiveness of traditional courses in challenging students pre-existing beliefs. One set of assumptions that underlies many introductory courses and majors, is that students will internalize critical thinking tools and be motivated to re-examine their existing beliefs without explicit cues to do so. This data suggests that those assumptions are not being met, and as such, students may need more explicit training in re-examining existing beliefs to develop this skill. Kowalski and Taylor (2009) compared sections of an introductory psychology course in which refutational lectures and readings were assigned with sections in which only refutational lecture was presented or only readings were assigned. Students who experienced the refutational lecture (with or without the accompanying reading) were more likely to correctly identify the item as a myth than students who had refutational reading alone. Preliminary findings from a first year seminar on the topic of Popular Psychological Myths $(n=7)$ found that one year later students correctly answered $63 \%$ of the items using the same questionnaire as the current study and only one item was incorrectly and confidently endorsed by a majority of the course (heroin is addictive). Although these are very preliminary findings, they are consistent with Kowalski and Taylor's findings of improved performance in an introductory psychology course taught with a specific focus on debunking myths (Kowalski \& Taylor, 2009). Given the prevalence of myths endorsed across the major, it is important for departments to consider where and when in the curriculum discipline-related myths are addressed.

While this study incorporated confidence ratings, it is still based on items presented in a True/False format. Several researchers, most recently Taylor and Kowalski (2012), have noted limitations of a true-false format. They contrasted student accuracy in the identification of myths when presented as true/false statements or in a forced-choice format. While they found that performance differed by myth, overall students were more accurate with a forced-choice format, perhaps because the multiple responses made them more carefully evaluate their belief. Future research in this area would benefit development of a more open-ended response format in which students could explain their answer and provide the evidence they are using to support it, although such a measure would be more difficult to score.

The findings of the present study highlight the importance of faculty teaching across disciplines to consider the misinformation with which their students are entering the course and to provide tools to help students challenge their beliefs. Since myths evolve over time, students 
will benefit from learning the skills to identify possible myths and research the evidence. While the present study focused on myths in psychology, these recommendations apply across disciplines.

\section{Acknowledgements}

I would like to thank James Laczkowski for his assistance with this research project and Thomas Sawyer and Alisa Beyer for their feedback on drafts of this manuscript.

Data from this study was presented at the 2012 Teaching Institute, Association for Psychological Science, Chicago, IL.

\section{Appendix}

\section{PSYCHOLOGY INFORMATION QUESTIONNAIRE}

For each item circle whether it is TRUE or FALSE.

Then note how CONFIDENT you are in that answer:

$\mathbf{1}=$ Not Sure

$\mathbf{2}=$ Moderately Confident

$\mathbf{3}=$ Very Confident

1. Psychology is defined as the study of mental disorders.

$\mathrm{T} \quad \mathrm{F} \quad$ Confident $=$

2. If you're unsure of your answer while taking a test, it's best to stick with your initial hunch.

T $\quad \mathrm{F} \quad$ Confident $=$

3. It can be easier to remember information if you are in the same emotional state as when you originally encoded that information.

$\mathrm{T} \quad \mathrm{F} \quad$ Confident $=$

4. Most "crack babies" end up with serious neurological deficits.
$\mathrm{T}$
F $\quad$ Confident $=$

5. Subliminal messages can be used to persuade others to purchase products.

$\mathrm{T} \quad \mathrm{F} \quad$ Confident $=$

6. Taste areas for sweet, sour, salty and bitter are well defined on the tongue.
$\mathrm{T}$
$\mathrm{F} \quad$ Confident $=$

7. ESP (extrasensory perception) has been empirically documented.

$\mathrm{T} \quad \mathrm{F} \quad$ Confident $=$

8. During "out of body" experiences, individuals can observe themselves from above.

$\mathrm{T} \quad \mathrm{F} \quad$ Confident $=$ 
Gaze, C.M.

9. Drug education programs (i.e., DARE) are effective in deterring drug use among teenagers.

$$
\mathrm{T} \quad \mathrm{F} \quad \text { Confident }=
$$

10. Individuals can learn information (e.g., new languages) while asleep.

$$
\mathrm{T} \quad \mathrm{F} \quad \text { Confident }=
$$

11. There is a genetic basis to schizophrenia.

$$
\mathrm{T} \quad \mathrm{F} \quad \text { Confident }=
$$

12. Most people who use heroin become addicted to it.

$$
\mathrm{T} \quad \mathrm{F} \quad \text { Confident }=
$$

13. Human memory works like a tape recorder or video camera, and accurately records the events we have experienced.
$\mathrm{T}$
F $\quad$ Confident $=$

14. We experience stress even when good things happen to us.

$$
\mathrm{T} \quad \mathrm{F} \quad \text { Confident }=
$$

15. Many adults were abused as children but do not remember the abuse

$$
\text { T } \quad \mathrm{F} \quad \text { Confident }=
$$

16. Hypnosis is useful for retrieving memories of forgotten events.
$\mathrm{T}$
$\mathrm{F} \quad$ Confident $=$

17. In criminal eyewitnesses, confidence is closely related to accuracy.

$$
\mathrm{T} \quad \mathrm{F} \quad \text { Confident }=
$$

18. Playing classical music (e.g., Mozart) to infants and children increases their intelligence.
$\mathrm{T}$
$\mathrm{F} \quad$ Confident $=$

19. Too much sugar causes hyperactivity in children.
$\mathrm{T}$
F $\quad$ Confident $=$

20. Babies who learned sign language as infants have a higher overall IQ.
$\mathrm{T}$
$\mathrm{F} \quad$ Confident $=$

21. Immediate contact between a mother and infant after birth is critical for bonding.
$\mathrm{T}$
F $\quad$ Confident $=$

22. You can "spoil" a baby if you respond to its demands too quickly.
$\mathrm{T}$
F $\quad$ Confident $=$

23. A baby's attachment for its mother is based on mom's filling the physiological need for food.

$\mathrm{T} \quad \mathrm{F} \quad$ Confident $=$


Gaze, C.M.

24. If you live long enough, you will eventually develop dementia.

$$
\mathrm{T} \quad \mathrm{F} \text { Confident }=
$$

25. The defining feature of dyslexia is seeing words backwards (e.g., "pal" instead of "lap").
$\mathrm{T}$
F $\quad$ Confident $=$

26. The polygraph ("lie detector") test is a highly accurate means of detecting dishonesty.
$\mathrm{T}$
$\mathrm{F} \quad$ Confident $=$

27. According to a classic research study, many people obeyed when given an order to administer powerful and potentially lethal shocks to someone.
$\mathrm{T}$
F $\quad$ Confident $=$

28. Most women experience a marked worsening of their moods during the premenstrual period.
$\mathrm{T}$
$\mathrm{F} \quad$ Confident $=$

29. Raising children similarly leads to similarities in their adult personalities.
$\mathrm{T}$
$\mathrm{F} \quad$ Confident $=$

30. Psychiatrists attend medical school and are responsible for administering psychiatric meds and may also provide therapy.
$\mathrm{T}$
F $\quad$ Confident $=$

31. Astrologers can predict your personality from the arrangement of stars and planets at your birth.

T F Confident $=$

32. People's responses to inkblots tell us a great deal about their personalities and propensities toward mental disorders.

$\mathrm{T} \quad \mathrm{F} \quad$ Confident $=$

33. People diagnosed with schizophrenia have a split personality.

T F Confident $=$

34. People who attempt to commit suicide do not talk about it.

T F Confident $=$

35. Eyewitness testimony is usually reliable.
$\mathrm{T}$
F $\quad$ Confident $=$

36. "Psychological profiling" has been shown to be an effective means of identifying criminals.

T $\quad \mathrm{F}$ Confident $=$ 
Gaze, C.M.

37. The suicide rate is higher among the elderly than among adolescents.

$\mathrm{T} \quad \mathrm{F} \quad$ Confident $=$

38. A large proportion of criminals are acquitted on the basis of the insanity defense.

$\mathrm{T} \quad \mathrm{F} \quad$ Confident $=$

39. Clinical judgment and intuition are the best means of combining information to reach a diagnosis for a patient.
$\mathrm{T}$
F $\quad$ Confident $=$

40. A well-trained psychotherapist can establish a person's true thoughts and problems by analyzing dreams.

$\mathrm{T} \quad \mathrm{F} \quad$ Confident $=$

41. All effective psychotherapies force individuals to confront the "root" causes of their problems in childhood.

T $\quad \mathrm{F} \quad$ Confident $=$

42. Electroconvulsive ("shock") therapy is a physically dangerous treatment.

$\mathrm{T} \quad \mathrm{F} \quad$ Confident $=$

43. Opposites attract: People tend to have relationships with individuals who differ from them in their personality, interests, and attitudes.
$\mathrm{T}$
F $\quad$ Confident $=$

44. There's safety in numbers: The more people present at an emergency, the greater the chance that someone will intervene.
$\mathrm{T}$
F $\quad$ Confident $=$

45. Women talk more than men ("Men are from Mars, women are from Venus").
$\mathrm{T}$
F $\quad$ Confident $=$

46. Most people use only $10 \%$ of their brains.
$\mathrm{T}$
F $\quad$ Confident $=$

47. During sleep, your brain rests.
$\mathrm{T}$
F $\quad$ Confident $=$

48. There are striking stylistic differences between the two hemispheres of the brain, with the left being "analytic" and the right "holistic."
$\mathrm{T}$
$\mathrm{F} \quad$ Confident $=$

49. It is generally better to express anger openly than to hold it in.
$\mathrm{T}$
F $\quad$ Confident $=$

50. High self-esteem is necessary for high achievement.
$\mathrm{T}$
F $\quad$ Confident $=$ 
Gaze, C.M.

For ONE of the questions above, please tell us where you learned this information using this code:

$\mathbf{M}=$ media - TV (news, talk show, Dateline, 20/20), radio, movie, newspaper, magazine, book, etc.

$\mathbf{P}=$ personal experience

$\mathbf{C}=$ classroom knowledge

$\mathbf{O}=$ other--add your own source for this knowledge.

Please be as explicit as possible about how you know about each of these. For example if you think media is the source of your knowledge note if it was in a magazine article, which magazine, or which type of magazine, i.e., Newsweek, Discover, People, etc. So your answer might M (Oprah) or P (observing my younger siblings) or O (my aunt, who is a nurse, told me). YOU MAY LIST MULTIPLE SOURCES in the order of their importance in learning about the information.

Question \#

Source(s):

(detail

\section{References}

Brown, L.T. (1984). Misconceptions About Psychology Aren't Always What They Seem. Teaching of Psychology, 11, 75-78. doi: 10.1207/s15328023top1102_3_3

Gardner, R. M., \& Dalsing, S. (1986). Misconceptions About Psychology Among College Students. Teaching Of Psychology, 13, 32-34. doi: 10.1207/s15328023top1301_9

Griggs, R.A., \& Ransdell, S. E. (1987). Misconceptions Tests or Misconceived Tests. Teaching Of Psychology, 14, 210-213. doi: 10.1207/s15328023top1404_4

Kowalski, P., \& Taylor, A. (2009). The Effect of Refuting Misconceptions in the Introductory Psychology Class. Teaching of Psychology, 36 (3), 153-159. doi: 10.1080/00986280902959986

Kuhle, B. X., Barber, J. M., \& Bristol, A. S. (2009). Predicting Students' Performance in Introductory Psychology from Their Psychology Misconceptions. Journal of Instructional Psychology, 36 (2), 119-124.

Lilienfeld, S. O. (2010). Confronting Psychological Misconceptions in the Classroom: Challenges and Rewards. APS Observer, 23 (7), 17; 36-39.

McKeachie, W. J. (1960). Changes in Scores on the Northwestern Misconceptions Test in Six Elementary Psychology Courses. Journal of Educational Psychology, 51, 240-244. doi: $10.1037 / \mathrm{h} 0048569$

Ruble, R. (1986). Ambiguous Psychological Misconceptions. Teaching of Psychology, 75, 3436. doi: $10.1207 / \mathrm{s} 15328023$ top1301_10 
Standing, L. G., \& Huber, H. (2003). Do Psychology Courses Reduce Belief in Psychological Myths? Social Behavior and Personality, 57, 585-592. doi: 10.2224/sbp.2003.31.6.585

Taylor, A. K., \& Kowalski, P. (2004). Na1ve Psychological Science: The Prevalence, Strength, and Sources of Misconceptions. Psychological Record, 54, 15-25.

Taylor, A.K., \& Kowalski, P. (2012). Students' Misconceptions in Psychology: How You Ask Matters...Sometimes. Journal of the Scholarship of Teaching and Learning, 12, 62-77.

Vaughan, E. D. (1977). Misconceptions About Psychology Among Introductory Psychology Students. Teaching of Psychology, 4, 138-141. doi: 10.1207/s15328023top0403_9 